\title{
A STUDY OF THE ANTIFIBRINOLYSIN ACTIVITY IN HUMAN PLASMAS DURING PATHOLOGICAL STATES ${ }^{1}$
}

\author{
By M. MASON GUEST, BYRNE M. DALY, ARNOLD G. WARE, \\ AND WALTER H. SEEGERS
}

\author{
(From the Department of Physiology, Wayne University College of Medicine, \\ Detroit, Michigan)
}

(Received for publication June 1, 1948)

Utilizing the methods described in the preceding report (1), a study of the antifibrinolysin activity in plasmas from patients of Receiving and Harper Hospitals in the City of Detroit has been initiated. The antifibrinolysin in human plasma which was assayed inactivates bovine fibrinolysin. The results indicate that there is a tendency for the antifibrinolysin activity to be increased in a number of different diseases. The conditions studied include: pneumonias, coronary thrombosis, pernicious anemia, secondary anemia, cirrhosis of the liver, intestinal obstructions and acute bacterial endocarditis. Other pathologies may also result in an increased plasma antifibrinolysin activity, although no increase was found in patients convalescing from fractures.

\section{EXPERIMENTAL}

Blood was obtained from the antecubital vein. Seven parts of whole blood were immediately mixed with one part of 1.85 potassium oxalate. Hematocrits were determined and the plasma separated by centrifugation. The plasma was immediately defibrinated by adding small increments of dry Thrombin Topical (Parke, Davis and Company). After each addition of thrombin a small portion of the plasma was tested for the presence of fibrinogen by the addition of a small amount of thrombin. If a clot formed or fibrin threads appeared another small amount of dry thrombin was added to the main plasma sample. When the plasma had been completely defibrinated the antifibrinolysin assay was performed immediately, or if this were not possible the plasma was stored at $-20^{\circ} \mathrm{C}$.

The antifibrinolysin assays were carried out as described in the preceding report (1). Plasma dilutions were made which brought the dissolving time of the standardized clots to between 200 and 300 seconds. From the dissolving time of the clot on the $x$ axis (Figure 4 of preceding report [1]), the intercept with the curve was determined and the coordinate extended to the $y$ axis from which could be estimated the unit activity of antifibrinolysin in the plasma. Correction was made in each

\footnotetext{
1 Aided by a grant from the U. S. Public Health Service.
}

case for dilution and the addition of oxalate. Antifibrinolysin activity is expressed as units per milliliters of undiluted plasma.

\section{RESULTS}

Figure 1 is a graphical representation of the results. The plasmas of individuals exhibiting no obvious pathology were relatively uniform in antifibrinolysin activity. The mean for the normal group of six subjects was 79 units per $\mathrm{ml}$. with the lowest value 59 units per $\mathrm{ml}$. and the highest 98 units per $\mathrm{ml}$. In contrast, marked variations in antifibrinolysin activity were found in plasmas from diseased individuals. In some cases the activity was found to be within the normal range, but extremely high values were obtained in other patients suffering from the same disease.

An individual in which intestinal obstruction was complicated by lymphogranuloma had the highest unit activity of antifibrinolysin in the plasma, 258 units per $\mathrm{ml}$. In decreasing order of the mean antifibrinolysin activity unitage per milliliter of undiluted plasma the pathologies were

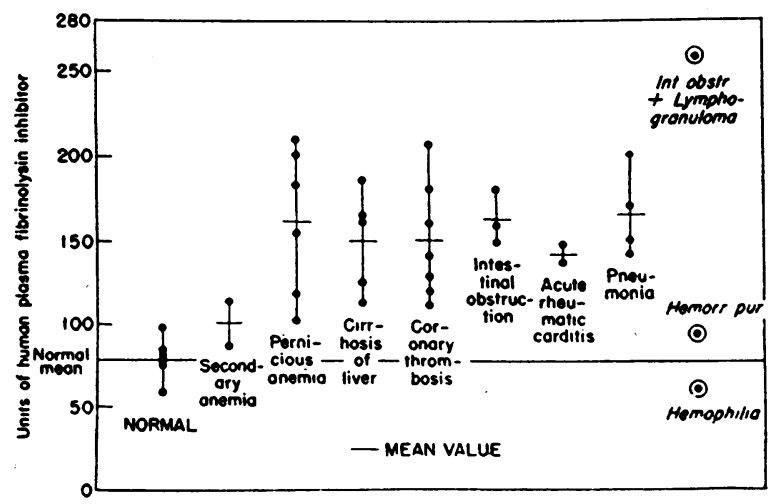

Fig. 1. Graphical Representation of Plasma Antifibrinolysin Levels in Normal and Diseased Human INDIVIDUALS

The points indicate individual determinations; the short horizontal cross-lines the mean value for the group. 
pneumonias, intestinal obstruction, pernicious anemia, cirrhosis of the liver, coronary thrombosis, acute bacterial endocarditis and secondary anemia. However, in order to establish the relative levels a much larger series would be required. One case of hemorrhagic purpura and one of true hemophilia exhibited activity within the normal range.

\section{DISCUSSION}

The role of fibrinolysin and antifibrinolysin in the physiology and pathology of the animal organism has not been established. Evidence has been presented that active fibrinolysis occurs in shock (2) and that it takes place in the blood of cadavers in which death had occurred rapidly (3). In contrast patients suffering from acute streptococcal infections (4) and those exhibiting acute or chronic medical illnesses of a variety of types tend to have a higher than normal plasma antifibrinolysin activity. It has also been reported that the antistreptokinase activity of plasma increases during streptococcal infections $(4,5)$. Thus it appears that although a fibrinolytic tendency may occur in restricted circumstances, the more common reaction of the organism to injury involves an increase in the activity of those factors which tend to neutralize or prevent the formation of free fibrinolysin in the plasma.

Grob (6) has indicated that the ability to control leucoprotease (fibrinolysin?) and serum antiprotease (antifibrinolysin?) may be important and useful in the study and understanding of inflammations ; protection of joint and other structures from proteolytic action; experimental arteriosclerosis and arterionecrosis; coagulation of blood; prolonging the action of insulin; release of thyroglobulin from the thyroid gland; bacterial growth and sulfonamide action; etc. It is possible that antifibrinolysin may have an additional function or functions in addition to the property of fibrinolysin inactivation.

The physiological consequence of an excess of free fibrinolysin in the plasma of the intact organism is difficult to determine. Fibrinolysin injected into a vein of a dog is rapidly inactivated by the excess antifibrinolysin in the plasma (7). From in vitro studies it is known that fibrinolysin inactivates prothrombin (8) and causes decomposi- tion of fibrinogen and fibrin (9). Its effect upon other proteins, cell membranes, cell and vascular permeability and upon specific tissues is uncertain.

It is hoped that the assay method presented in this and the preceding report may offer a tool which will help in determining the significance of fibrinolytic and antifibrinolytic blood factors in the economy of the organism.

\section{SUMMARY}

The assay in human patients of the plasma antifibrinolysin which inactivates bovine fibrinolysin has revealed that this antifibrinolysin activity is increased in pernicious anemia, pneumonias, intestinal obstruction, acute bacterial endocarditis, and coronary thrombosis. One patient with true hemophilia and another suffering from hemorrhagic purpura showed no evidence of either an increase or a decrease in plasma antifibrinolysin activity.

\section{BIBLIOGRAPHY}

1. Guest, M. M., Daly, B. M., Ware, A. G., and Seegers, W. H., A study of antifibrinolysin activity in the plasmas of various animal species. J. Clin. Invest., 1948, 27, 785.

2. Tagnon, H. J., Levenson, S. M., Davidson, C. S., and Taylor, F. H. L., The occurrence of fibrinolysis in shock, with observations on the prothrombin time and the plasma fibrinogen during hemorrhagic shock. Am. J. M. Sc., 1946, 211, 88.

3. Judine, S. S., La transfusion du sang de cadavre aux êtres humains. Presse méd., 1936, 44, 68.

4. Commission on Acute Respiratory Diseases, Studies of streptococcal fibrinolysis. IV. Clinical application of a quantitative antifibrinolysin test. J. Clin. Invest., 1946, 25, 352.

5. Commission on Acute Respiratory Diseases in collaboration with Kaplan, M. H., A quantitative study of the fibrinolysin-antifibrinolysin reaction. Science, 1945, 101, 120.

6. Grob, D., Proteolytic enzymes. II. The physiological significance of the control of their activity, especially with respect to bacterial growth. J. Gen. Physiol., 1946, 29, 249.

7. Guest, M. M., Murphy, R. C., Bodnar, S. R., Ware, A. G., and Seegers, W. H., Physiological effects of a plasma protein: Blood pressure, leucocyte concentration, smooth and cardiac muscle activity. Am. J. Physiol., 1947, 150, 471.

8. Seegers, W. H., and Loomis, E. C., Prothrombin and fibrinolysin. Science, 1946, 104, 461.

9. Seegers, W. H., Nieft, M. L., and Vandenbelt, J. M., Decomposition products of fibrinogen and fibrin. Arch. Biochem., 1945, 7, 15. 